\title{
Corrosion Behavior of API 5L X52 Carbon Steel Coated by Oxygen Plasma Discharge
}

\author{
D. Mansour ${ }^{1}$, B. Demri, ${ }^{2, *}$, S. Belkaid ${ }^{3}$ \\ ${ }^{1}$ Department of Corrosion, Division of Technologies \& Development, Algeria \\ ${ }^{2}$ Department of Basic Sciences, Ecole Nationale Polytechnique, Algeria \\ ${ }^{3}$ Laboratory of Electrochemistry- Corrosion, Metallurgy and Chemistry, University of Science and Technology Houari Boumediene \\ (USTHB), Algeria
}

Copyright $(2015$ by authors, all rights reserved. Authors agree that this article remains permanently open access under the terms of the Creative Commons Attribution License 4.0 International License.

\begin{abstract}
Surface treatments of materials have attracted intensive studies in recent years, and considered as an important way for providing protection properties. In this paper, oxygen plasma treatment was used on API 5L X52 carbon steel. The produced deposit was characterized by different methods; optical and electronic microscopy, microhardness measurements and $\mathrm{X}$ rays diffraction. The resulting layer has been evaluated by electrochemical methods and pitting corrosion tests. The results showed that $\mathrm{Fe}_{2} \mathrm{O}_{3}$, which resulted from coating treatment by oxygen plasma, improved the superficial microhardness of steel. In chemical terms, pitting corrosion tests in corrosive solution showed a clear decrease of the weight loss and pitting percentage in coated coupons. Moreover, electrochemical corrosion tests (linear polarization and electrochemical impedance spectroscopy tests) showed that the produced deposit after coating gived a good protection against corrosion. This study demonstrates that oxygen implantation provides protective properties to API 5L X52 carbon steel.
\end{abstract}

Keywords Carbon Steel, Oxygen Plasma, Corrosion, SEM, Electrochemical Methods

\section{Introduction}

Carbon steels and particularly API 5L X52 are widely used in oil and gas industry. This is essentially due to economical consideration. However, in the case of petroleum industry, such steels exhibit a poor corrosion resistance. In order to increase their resistance to corrosion, many methods have been proposed.

The use of chemical inhibitors is one of the most practical methods for metals protection against corrosion in acidic media [1-4]. Ion implantation is a common technique used to modify the near surface materials. It leads to the formation of thin surface layers of stable or non stable components. As a consequence it has been considerated that the corrosion resistance of various materials could be improved by ion implantation. Nowadays, no general law can be deduced from the literature and implantation can either enhance [5] or reduce the corrosion phenomenon $[6,7]$.

The present work focuses on the surface modification of API 5L X52 steel by oxygen plasma treatment to obtain an iron oxide layer. Iron oxides and particularly $\mathrm{Fe}_{2} \mathrm{O}_{3}$ provide very interesting physico-chemical properties. They are well known to show magnetical, electronical and electrochemical properties. These oxides have also good mechanical properties in terms of hardness and wear resistance [8-11].

Because of these reasons, coating various materials with iron oxides films are extensively investigated in the last few years. Iron oxides films are prepared by using various methods.

For the protection of steels, the surface oxide iron film is generally produced by thermal oxidation in air under temperatures ranging from 350 to $650^{\circ} \mathrm{C}$ for periods of time, ranging from few minutes to several hours [12-15].

Physical vapor deposition (PVD), thermal evaporation (TE) and ion beam assisted deposition (IBAD) have also been used to produce iron oxide films [16-18].

In most cases, produced iron oxide films are heterogeneous and consist on several phases. The existence of hematite $\left(\mathrm{Fe}_{2} \mathrm{O}_{3}\right)$ and magnetite $\left(\mathrm{Fe}_{3} \mathrm{O}_{4}\right)$ has been reported by several workers [13-17]. However, Shieu and al [14] have reported the formation of $\gamma-\mathrm{Fe}_{2} \mathrm{O}_{3}$ phase in addition to $\alpha-\mathrm{Fe}_{2} \mathrm{O}_{3}$ and $\mathrm{Fe}_{3} \mathrm{O}_{4}$.

The aim of this work is to grow an iron oxide film on the surface of an API 5L X52 by using oxygen plasma treatment. This technique of coating is well described by M. Booth [19]. In this method, an electric glow discharge in oxygen residual pressure of few mbars under a voltage of few kilo electron-volts was used. The sample was the cathode, and the vacuum system was the anode. This method can be considered as low energy ion-implantation technique. As it is based on the bombardment of the substrate with oxygen ions, it is expected that the treated samples will exhibit good mechanical properties in addition to the improvement of the 
corrosion resistance. API 5L X52 is a variety of steels widely used in pipelines; however it is subject to aqueous and bacterial corrosions.

The produced samples are then characterized by means of optic microscopy, scanning electron microscopy (SEM) coupled with energy dispersive X-ray analysis (EDX) and micro-hardness measurements. Steel peaces are submitted to pitting corrosion tests, linear polarization and electrochemical impedance spectroscopy.

\section{Experimental Procedure}

\subsection{Materials}

The material used in this study was an API 5L X52 carbon steel with the following chemical composition given by $\mathrm{X}$-ray fluorescence (in atoms percent) : $0.2 \% \mathrm{C}, 96.35 \% \mathrm{Fe}$, $0.078 \% \mathrm{Cr}, \quad 0.078 \% \mathrm{Ni}, \quad 1.179 \% \mathrm{Mn}, \quad 0.15 \% \mathrm{Si}, \quad 0.17 \% \mathrm{Cu}$, $0.04 \% \mathrm{~V}, 0.01 \% \mathrm{~S}, 0.01 \% \mathrm{P}, 0.01 \% \mathrm{Al}, 0.05 \% \mathrm{~K}$, and $0.07 \% \mathrm{Cl}$. Steel samples consist of parallelepipeds of $10 \times 10 \times 3 \mathrm{~mm}$. The surface of the samples was mechanically polished with silicon carbide abrasive paper with decreasing granulometry. Mirror aspect was obtained by alumina polishing (granulometry of $1 \mu \mathrm{m}$ ). Finally, steel samples were cleaned with water and ethanol, and dried under atmospheric conditions. All the samples were weighted with a Sartorius M2P balance and their dimensions were measured with a sensitivity of $10^{-2} \mathrm{~mm}$.

\subsection{Oxygen plasma treatment}

Surface treatment of API 5L X52 samples was performed at room temperature by glow electrical discharge created between two electrodes set into cylindrical glass enclosure. The steel samples which act as the cathode were situated at about $10 \mathrm{~cm}$ from the anode. The applied voltage was about $1000 \mathrm{~V}$ and treatment duration was about $50 \mathrm{~h}$. During the electrical discharge, the oxygen pressure was maintained around $8.10^{-2}$ Torr and the current sample, measured under these conditions, was about $15 \mathrm{~mA}$.

\subsection{Characterization}

Optical and electron microscopy

To observe the surface modification of the steel pieces, both optical and electron microscopes were applied. The optical microscopy observations were performed by an Olympus metallographic microscope equipped with Analysis images analyzer and Atlas phase's treatment softwares.

For the electron microscopy observations, a Jeol JSM-63 $60 \mathrm{LV}$ scanning electron microscope with an EDAX energy dispersive analyzer was used.

Microhardness measurements
The microhardness of the samples was measured with Schimadzu-Vickers-HMVM microhardness apparatus, under a load of $50 \mathrm{~g}$. The measurements were done at scattered points of the surface.

\subsection{Evaluation of Corrosion Resistance}

\section{Pitting corrosion tests}

Pitting corrosion tests of steel samples were realized by immersion during two (02) hours in a ferric trichloride solution $\left(\mathrm{FeCl}_{3}\right)$ at temperatures of 22 and $50^{\circ} \mathrm{C}$. At the end of tests, the samples were rinsed with distilled water, immersed in ethanol, dried in air, and then weighted for evaluating the weight loss.

\section{Electrochemical corrosion tests}

Electrochemical corrosion tests were realized in a glass chemical cell, with a spherical shape, provided with openings through which electrodes were introduced and system was degassed; The working electrodewas prepared with API 5L X52 carbon steel (with or without oxygen plasma treatment). The reference electrode was a saturated calomel electrode (ECS), linked to sample via Luggin capillary. The two auxiliary electrodes were made up of platinum.

Tests were carried out in $3.5 \% \mathrm{NaCl}$ solution $(\mathrm{pH} 7.5)$ shacked and degassed by continuous bubbling of nitrogen gas. Tests were done under atmospheric pressure, and at $25^{\circ} \mathrm{C}$. Electrochemical evaluationwas realized using different methods: corrosion potential evolution, linear potential resistance (Rp) and electrochemical impedance spectroscopy (EIS). These measurements were performed on EGG 273 A potentiostat galvanostat, equipped with M $352 / 252$ acquisition calculation software. This software calculates the values of the corrosion potential $\left(\mathrm{E}_{\text {corr }}\right)$, corrosion current density $\left(\mathrm{j}_{\text {corr }}\right)$ and corrosion rate $\left(V_{\text {corr }}\right)$ in mm per year.

The determination of $\mathrm{Rp}$ was realized by linear polarization in a range of $\pm 10 \mathrm{mV}$ around the free potential, with increments of of $0.1 \mathrm{mV}$ and $0.6 \mathrm{~s}$ time sweep, giving scanning speed of about $0.17 \mathrm{mV} / \mathrm{s}$. From this technique, $R_{p}$ values obtained were used to calculate the corrosion current density, according to Stern-Geary relation [20]:

$$
i_{\text {coor }}=\frac{\beta}{R_{p}}
$$

Where $\beta$ is the Stern-Geary coefficient and a value of $0.026 \mathrm{~V} /$ decade was considered.

Faraday's law can be used to relate the corrosion current density to the corrosion rate using the next relation [20]:

$$
V_{\text {corr }}=96500 \frac{i_{\text {corr }}}{\delta} E W
$$

Where $E W$ is the equivalent weight and $\delta$ is the density. The EIS measurements of the coated and uncoated API 5L 
$\mathrm{X} 52$ steel were carried out at the OCP in $3 \% \mathrm{NaCl}$ aqueous solution. The frequency was varied from $10^{5} \mathrm{~Hz}$ to $10 \mathrm{mHz}$ using $10 \mathrm{mV}$ amplitude sinusoidal signal. The analysis of impedance spectra was done by fitting the experimental results to equivalent circuits using Zview software. The quality of fitting to equivalent circuit was judged by the chi-square value (the sum of the square of the differences between theoretical and experimental points).

\section{Results and Discussion}

\subsection{Morphology and Structural Analysis}

After oxygen plasma treatment, the steel samples showed a color between dark blue and black (micrographs not illustrated). The blue-black color denotes the formation of surface oxide * and such color has been observed by other workers after ion implantation [19].

The SEM observations on the surface of non treated samples revealed homogenous look and clean surface as shown in figure*1. EDS analysis, corresponding to this micrograph, given in the same figure indicated the presence of iron and carbon. The atomic percentages of these elements were respectively $87.01 \%$ and $12.99 \%$. The excess of carbon can be attributed to the surface contamination in mechanical polishing. The structural analysis of the bulk by XRD has revealed the existence of a unique phase, identified as an iron-manganese phase corresponding to $\mathrm{Fe}_{19} \mathrm{Mn}$ [21].

The SEM micrograph of oxygen plasma treated steel, showed inclusions forming swellings of different sizes (figure 2). An analog behavior has been observed by Lee et al (cette reference n'existe pas) [22]. These authors have observed the degradation of oxide layer as the result of prolonged oxygen plasma bombardment, as the post oxidizing time increase. EDS analysis corresponding to this micrograph indicates that the surface layer was essentially composed of $\mathrm{Fe}(26.19 \mathrm{at} \%)$ and $\mathrm{O}(61.61 \mathrm{at} \%)$. Beside these main constituents, some surface impurities (Al, Na, C) arising from the plasma treatments, (electrodes, pumping oils ....), were detected.

The XRD analysis of treated samples has revealed the formation of an iron oxide phase corresponding to hematite $\left(\alpha-\mathrm{Fe}_{2} \mathrm{O}_{3}\right)$, in addition to the $\mathrm{Fe}_{19} \mathrm{Mn}$ phase [21]. In this work, the magnetite $\left(\mathrm{Fe}_{3} \mathrm{O}_{4}\right)$ has not been detected. This was probably due to the stability of hematite. In addition $\mathrm{Fe}_{3} \mathrm{O}_{4}$ phase consists of thin layer at the interface between oxide (hematite) and the metal [20]. However, magnetite could be detected at the surface when samples were heated at temperature, ranging from $400^{\circ} \mathrm{C}$ to $500^{\circ} \mathrm{C}$ [11].

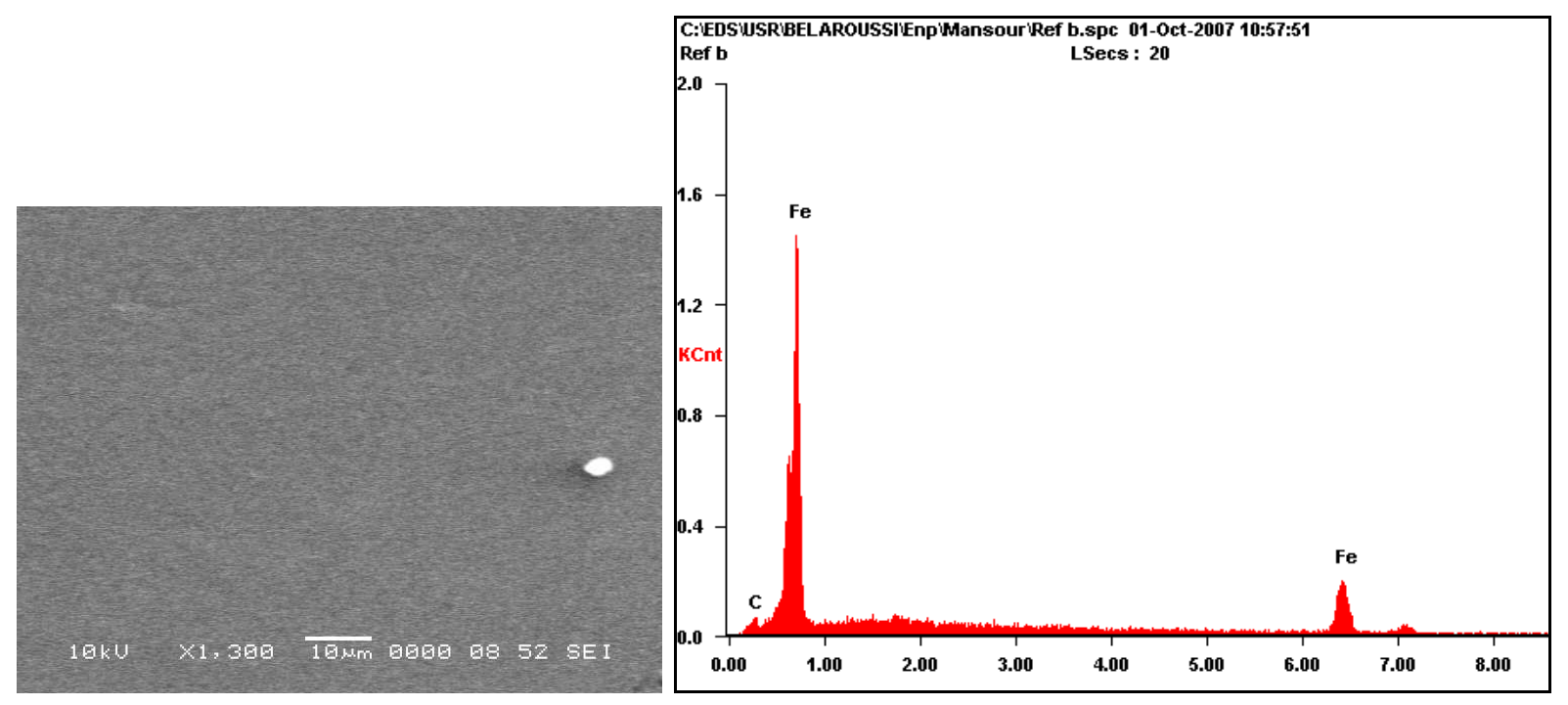

Figure 1. Electronic micrograph with EDS analysis of uncoated sample.
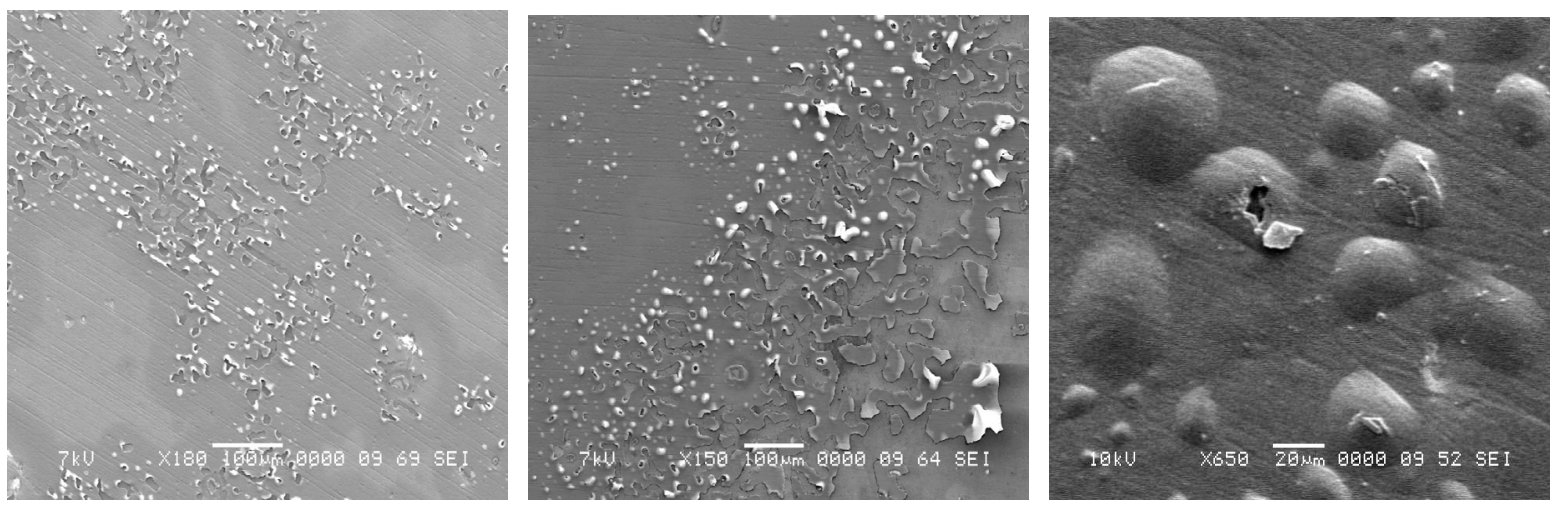


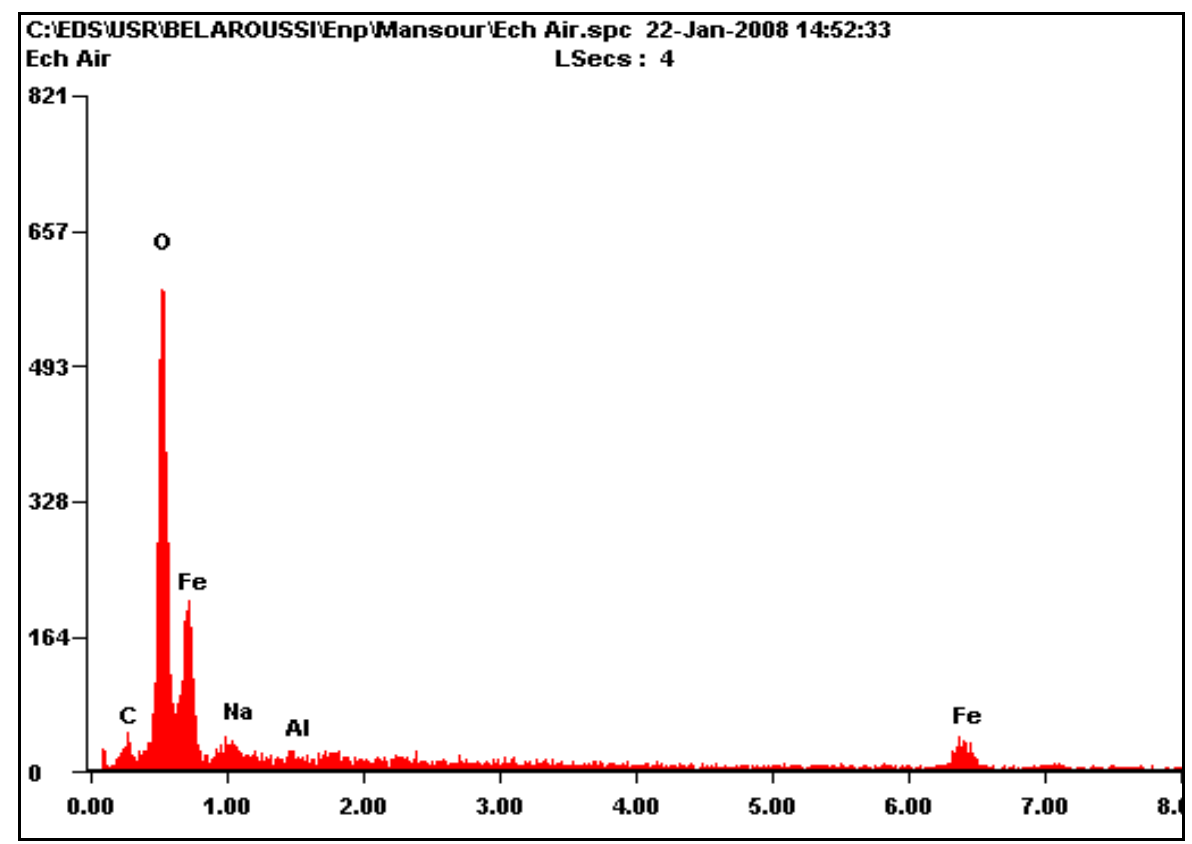

Figure 2. Electronic micrograph with EDS analysis of coated sample.

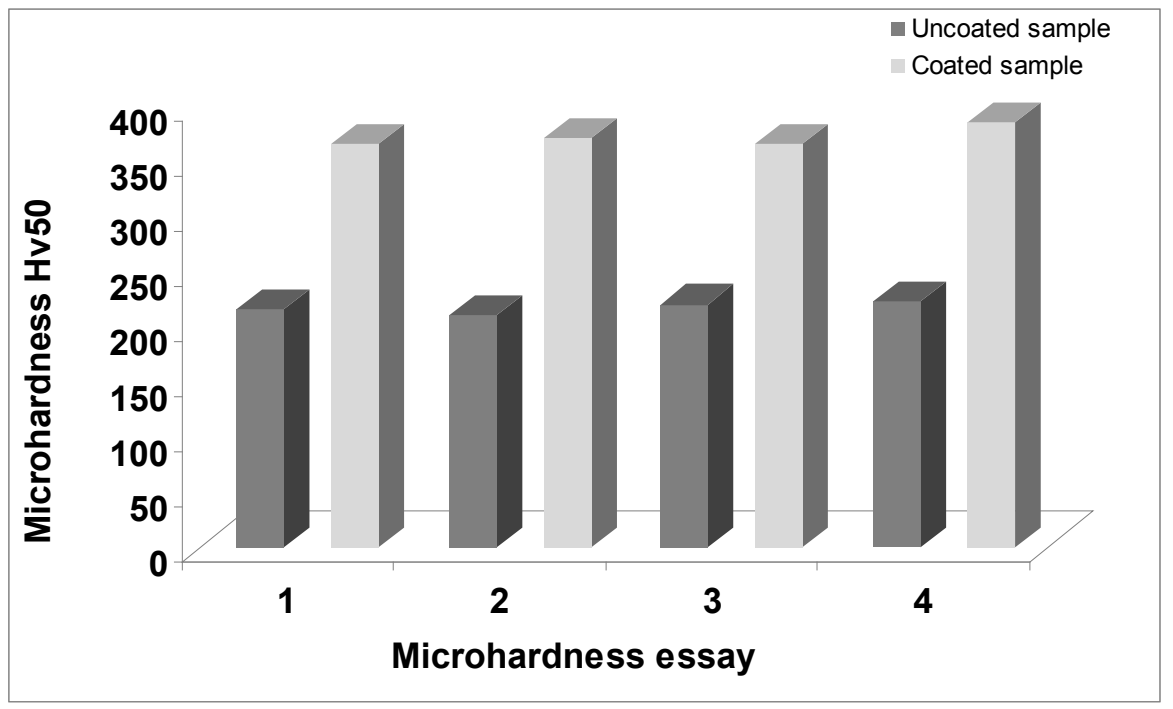

Figure 3. Microhardness $\mathrm{Hv}_{50}$ measurements on steel samples before and after oxygen plasma treatment.

\subsection{Microhardness}

The microhardness measurements were summarized in figure 3 . The results indicated that oxygen plasma treatment increased, and consequently surface hardness of steel samples were increased. The average microhardness increased from $218 \mathrm{HV}_{50}$ without treatment to around 374 $\mathrm{HV}_{50}$ with treatment. This result corresponded to an increase of approximately $70 \%$. This states that oxygen implantation improves the steel superficial microhardness, and that the indenter used touches only the treated layer and it does not attain the substratum. Our results are in good agreement with the values reported in literature, using the ion implantation method. This method operates usually at higher energies (several hundred of $\mathrm{keVs}$ ) and the hardness was increased by a factor of $100 \%$ and more [19-20]. It is well known that ion implantation impart changes in the superficial microstructure of the coated substrate, thus it allows the modification of mode deformation by introducing for example, the obstacles to dislocation movement, the formation of second phase or thin dispersion of hard precipitate.

In comparison with other published results, some authors have generally reported the improvement of about $25 \%$ to $40 \%$ when surface oxides were formed by thermal treatments $[15,23]$.

\subsection{Immersion Corrosion Tests}

The results of corrosion resistance tests are shown in table 1. These results showe that oxygen plasma coated steel samples, present smaller weight losses and pitting percentages as compared to uncoated pieces. It is known that 
anodic and cathodic sites are not always uniformly distributed over the surface, particularly when the sample is coated, and therefore, it is possible to have less anodic than the coated one, and for a smaller weight loss to have resulted. In contrast, on the freely corroding samples, the number and distribution of anodic and cathodic sites it can be assumed to have similar results in each case. However, no significant differences in behavior were observed at room temperature and at $50^{\circ} \mathrm{C}$.

Table 1. Corrosion resistance essays results.

\begin{tabular}{|c|c|c|c|c|}
\hline & \multicolumn{2}{|c|}{ Test temperature of $50^{\circ} \mathrm{C}$} & \multicolumn{2}{|c|}{ Test temperature of $22^{\circ} \mathrm{C}$} \\
\hline & $\begin{array}{c}\text { Weight loss } \\
\left(\mathrm{mg} / \mathrm{cm}^{2}\right)\end{array}$ & $\begin{array}{c}\% \text { of } \\
\text { pitting }\end{array}$ & $\begin{array}{c}\text { Weight loss } \\
\left(\mathrm{mg} / \mathrm{cm}^{2}\right)\end{array}$ & $\begin{array}{c}\% \text { of } \\
\text { pitting }\end{array}$ \\
\hline $\begin{array}{c}\text { Uncoated } \\
\text { samples }\end{array}$ & 200 & 79.4 & 171 & 77.6 \\
\hline $\begin{array}{c}\text { Coated } \\
\text { samples }\end{array}$ & 122 & 57.4 & 147 & 52.8 \\
\hline
\end{tabular}

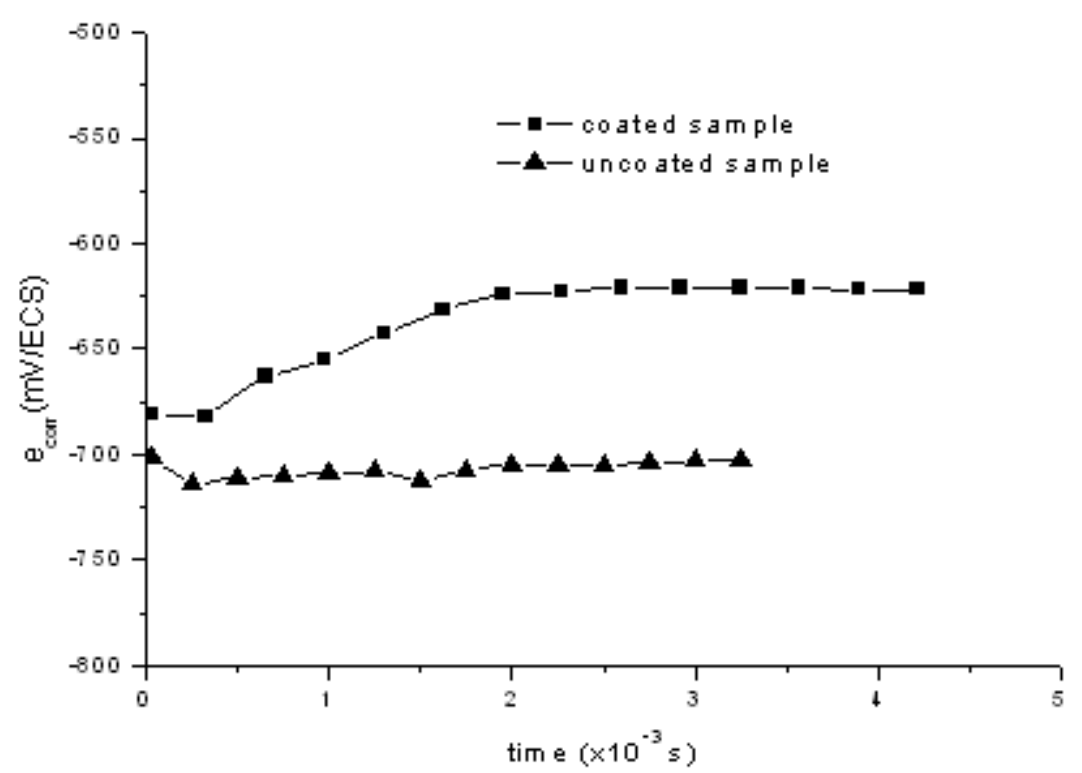

Figure 4. Time dependence of corrosion potentials for coated and uncoated API 5L X52 in $\mathrm{NaCl} 3 \%$ solution.

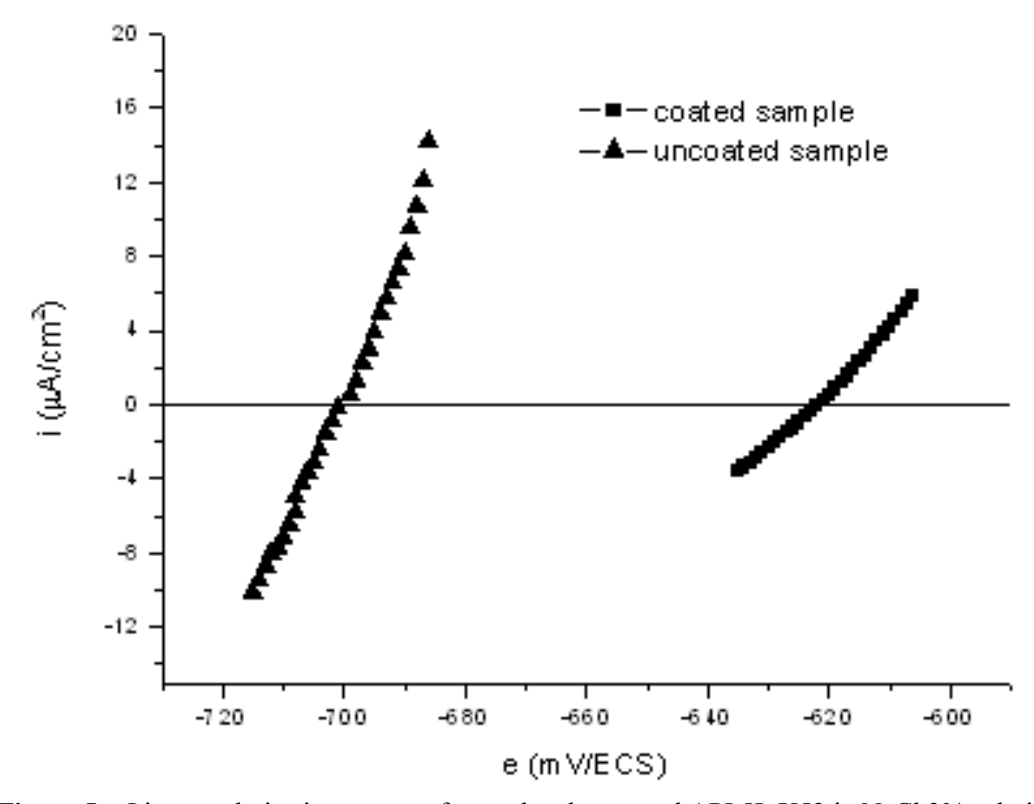

Figure 5. Linear polarisation curves of coated and uncoated API 5L X52 in NaCl 3\% solution.
Figure 4 shows the time dependence of corrosion potential of the coated and uncoated API 5L X52 carbon steel electrodes. For the uncoated specimen, corrosion potential changed slightly to reach steady-state values of about -703 $\mathrm{mV} / \mathrm{ECS}$. When the specimen was coated by oxygen plasma treatment, corrosion potential showed sharp increase before gradual stabilization at about $-622 \mathrm{mV} / \mathrm{ECS}$. The difference between corrosion potential values states that coated sample is nobler than the substrate, which leads to a polarisation of the steel in the anodic region. This can be attributed to the low electrochemical activity of coated metal with oxides film. This film has probably certain ability to inhibit corrosion process.

Figure 5. Linear polarisation curves of coated and uncoaed API $5 \mathrm{~L} X 52$ in $\mathrm{NaCl} 3 \%$ solution. 
Linear polarization resistance curve, widely used to monitor instantaneous corrosion rates of metal or alloy, exposed to corrosive environment, is suitable for the detection of changes in corrosion rate due to the presence of oxide film. Figure 5 shows the respective linear polarisation plots of coated and uncoated samples in $\mathrm{NaCl} 3 \%$ solution. Analytical data are shown in Table 2.

Table 2. Electrochemical parameters deduced from linear polarization curves.

\begin{tabular}{|c|c|c|c|c|}
\hline & $\begin{array}{c}\mathrm{E}_{\text {corr }} \\
(\mathrm{mV} / \mathrm{ECS})\end{array}$ & $\begin{array}{c}\mathrm{R}_{\mathrm{p}} \\
(\mathrm{K} \Omega \\
\left.\mathrm{cm}^{2}\right)\end{array}$ & $\begin{array}{c}\mathrm{I}_{\text {corr }} \\
\left(\mu \mathrm{A} \mathrm{cm}{ }^{-2}\right)\end{array}$ & $\begin{array}{c}\mathrm{V}_{\text {corr }} \\
(\mathrm{mm} \\
\left.\text { year }^{-1}\right)\end{array}$ \\
\hline $\begin{array}{c}\text { Uncoated } \\
\text { samples }\end{array}$ & -700 & 1.43 & 15.19 & ---- \\
\hline $\begin{array}{c}\text { Coated } \\
\text { samples }\end{array}$ & -622 & 3,75 & 5,78 & 2,30 \\
\hline
\end{tabular}

The corrosion current densities $I_{\text {corr }}$ were directly calculated from the polarization resistance $R \mathrm{p}$. Since $R \mathrm{p}$ is inversely proportional to Icorr, the sample with the highest $R \mathrm{p}$ (and thus the lowest Icorr) has the highest corrosion resistance. The oxide films due to oxygen plasma treatment on carbon steel were reported to be very thin (in $\mu \mathrm{m}$ range). Their stability and protective properties depend on the environment in which they were included such as solution $\mathrm{pH}$ and chloride ion concentration. The corrosion potential $E_{\text {corr }}$ undergoes a shift of $68 \mathrm{mV}$ toward anodic areas with the presence of oxide film. This is probably attributed to the inhibitive effect of the passivating film on the anodic oxidation reaction. Coated specimen resistance increased by $162 \%$ to $3.75 \mathrm{~K} \Omega \mathrm{cm}^{2}$ and corrosion current density, decreased by about $62 \%$ to $5.78 \mu \mathrm{A} / \mathrm{cm}^{2}$. From all these facts, it can be concluded that the stable layer of oxides formed on the coated steel demonstrated an improved protection from corrosion in the considered medium.

Figures. 6 and 7 show Nyquist impedance and Bode diagrams measured on the coated and uncoated samples. Electrode impedance is a complex number. Impedance spectra are normally displayed in Nyquist (complex plane) plot, where the opposite of the imaginary part of impedance is plotted against the real part, or in Bode plot in where both modulus of impedance and phase angle are plotted as function of frequency [24]. For an aqueous electrochemical system, when EIS was measured at the open circuit potentiel, the polarisation resistance $\mathrm{Rp}$, witch provides a measure of the protective efficiency of the surface layer, is given by [24]:

$$
R_{p}=\lim _{\omega \rightarrow 0} Z-\lim _{\omega \rightarrow \infty} Z
$$

where

$\omega(=2 \pi f)$ is the angular frequency.

$\lim _{\omega \rightarrow 0} Z$ is the low-frequency limit of impedance and

$\lim _{\omega \rightarrow \infty} Z$ is the electrolytical resistance of the solution which is generally negligible compared to $\lim _{\omega \rightarrow 0} Z$.

As observed in Nyquist diagrams (figure 6), one capacitive semicircle or two superposed semicircles can be observed over the whole frequency range. Moreover, the semicircle sizes tended to increase significantly with treated sample. It is obvious that oxygen plasma treatment has great influence on the impedance values of coated sample. Fig. 7 shows an increase in phase angle magnitude without the oxygen plasma treatment; this is exhibited at high frequency region. Its phase angle magnitude increases with the increased of dissolution in the steel/corrosion product interface [25]. Whereas the phase angle presents two maxima (for $\mathrm{f}=1$ and $10^{2} \mathrm{~Hz}$ ) indicating that two overlapping capacitive loops are present in the Nyquist plot for the two considered samples. In this case, a simple Randles circuit characterised by only one maximum for the phase angle (i.e. only one capacitive loop) is not sufficient for data fitting.

To investigate more the effectiveness of this treatment, an equivalent circuit was proposed in figure 8 , taking into account the oxide film formed by oxygen plasma treatment*as well as charge transfer reaction. Rs represents the solution resistance, $\mathrm{Rf}$ and CPEf represent the resistance and constant phase element of oxide films (or corrosion products films in the case of uncoated sample) on the electrode surfaces, Rct and CPEdl represent the charge transfer resistance and double layer constant phase element, respectively corresponding to the interfacial electrochemical reactions between electrolyte and metal. The constant phase element (CPE) is considered instead of capacitance in the fitting procedure because of the non ideal capacitive behaviour of the metal/ electrolyte system, observed from the flattening of the Nyquist diagrams. In fact neither real surfaces of solids in the active range, nor passive films on metallic substrates can be considered ideally homogeneous [26]. The high-frequency behaviour can be attributed to the passive oxide film and the low-frequency response to the interface metal/solution in the oxide film defects [26, 27]. As it is illustrated in figures 6 and 7, a good agreement has been obtained between experimental and fitting plots. This indicates that the model provided reliable description of the considered systems. 


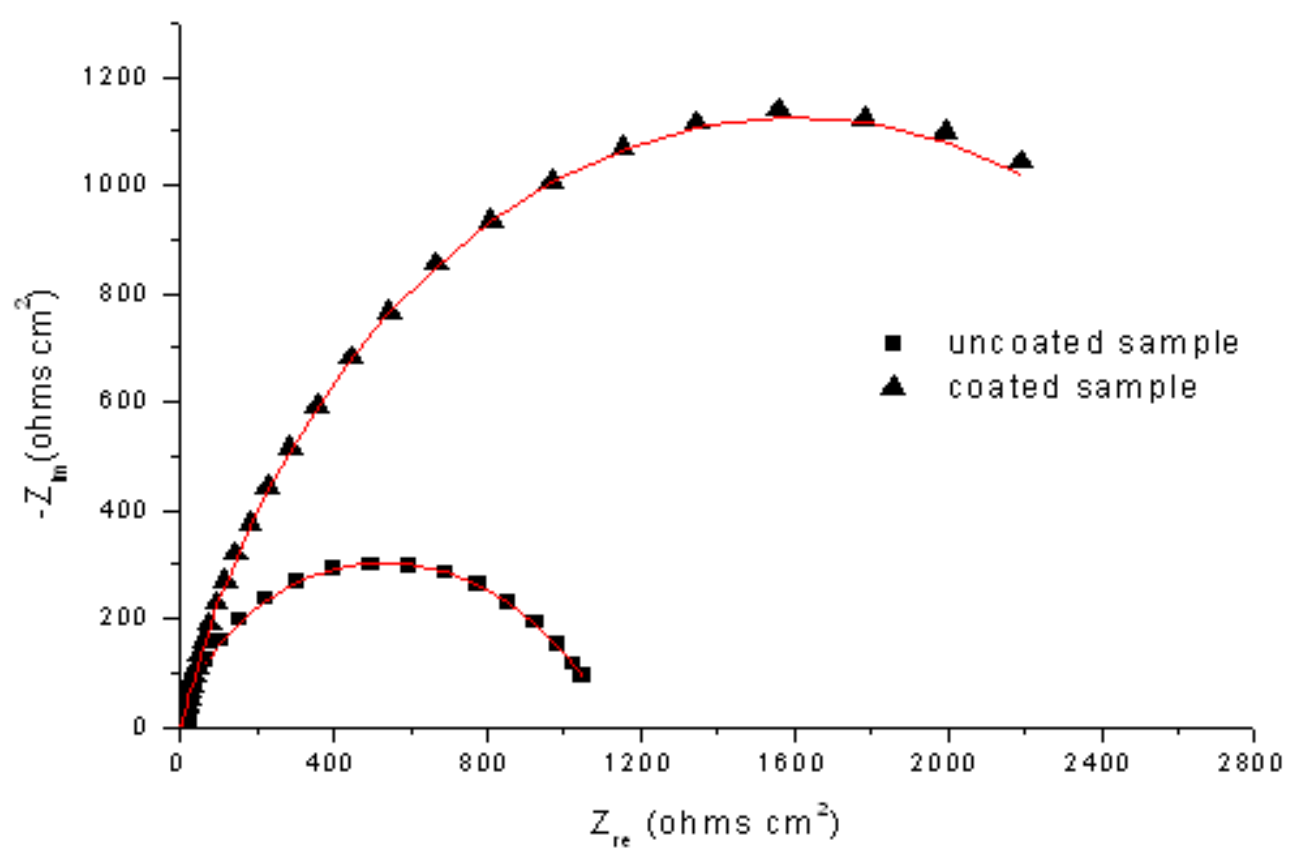

Figure 6. Nyquist plots of coated and uncoated API 5L X52 carbon steel in $\mathrm{NaCl} 3 \%$ solution. ( $\mathrm{J}$ ) and (K): experiment; solid line: simulated Nyquist diagrams using the equivalent circuit in Fig. 8
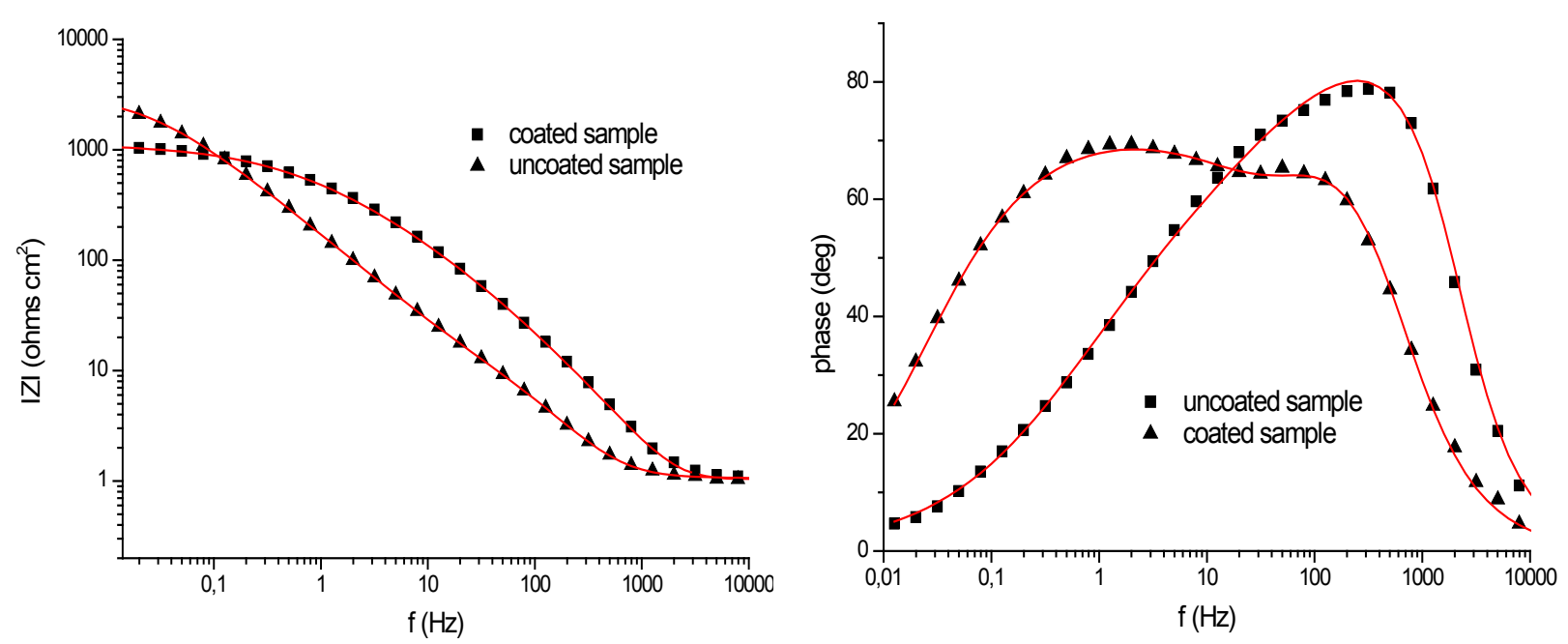

Figure 7. Bode plots of coated and uncoated API 5L X52 carbon steel in $\mathrm{NaCl} 3 \%$ solution. . (J) and (K): experiment; solid line: simulated Bode diagrams using the equivalent circuit in Fig. 8

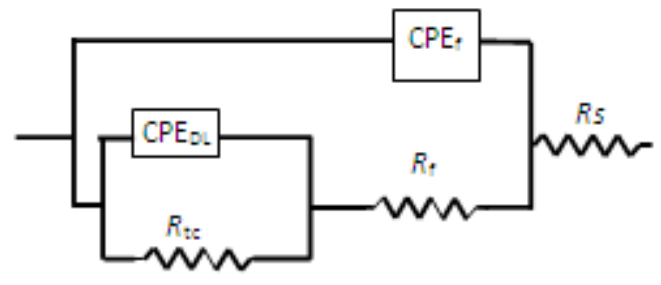

Figure 8. Electrical equivalent circuit for the interpretation of experimental diagrams of coated and uncoated steel in $\mathrm{NaCl} 3 \%$ solution

The main results obtained from fitting procedure are presented in Table. 3, where Q is the CPE constant $\left(\Omega^{-1} \mathrm{~cm}^{-2}\right.$ $\left.\mathrm{s}^{\mathrm{n}}\right)$ and $n$, the CPE exponent, is an adjustable parameter that lies between 0 and 1 . For $n=1$ the CPE describes an ideal capacitor with $\mathrm{Q}$ equal to the capacitance $\mathrm{C}$ and for $\mathrm{n}=0$, the CPE is an ideal resistor. In general, it is believed that the CPE is related to some type of heterogeneity of the electrode surface as well as to the fractal nature (roughness or porosity) of the surface [28].

Since $n<1$, the capacitance can be calculated from the CPE parameters determined experimentally using the following equation according to Boukamp [29]:

$$
C_{\mathrm{eq}}=\left(Q R_{\mathrm{ct}}\right)^{1 / n} / R_{\mathrm{ct}}
$$

where $R_{\mathrm{ct}}$ is the charge transfer resistance. Results are given in table 3 . 
Table 3. Fitting parameters of impedance for coated and uncoated API 5L X52 in NaCl 3\% solution.

\begin{tabular}{|c|c|c|c|c|c|c|c|c|}
\hline & $\begin{array}{c}R_{\mathrm{s}} \\
\left(\Omega \mathrm{cm}^{2}\right)\end{array}$ & $\begin{array}{c}Q_{\mathrm{f}} \\
\left(\Omega^{-1} \mathrm{~cm}^{-2} \mathrm{~s}^{\mathrm{n}}\right)\end{array}$ & $\begin{array}{c}R_{\mathrm{f}} \\
\left(\Omega \mathrm{cm}^{2}\right)\end{array}$ & $\mathrm{n}_{\mathrm{f}}$ & $\begin{array}{c}Q_{d l} \\
\left(\Omega^{-1} \mathrm{~cm}^{-2} \mathrm{~s}^{\mathrm{n}}\right)\end{array}$ & $\begin{array}{c}R_{\mathrm{ct}} \\
\left(\Omega \mathrm{cm}^{2}\right)\end{array}$ & $\begin{array}{c}\mathrm{n}_{\mathrm{dl}} \\
\left(\Omega \mathrm{cm}^{2}\right)\end{array}$ & $\begin{array}{c}C_{\mathrm{eq}} \\
\left(\mathrm{mF} \mathrm{cm}^{-2}\right)\end{array}$ \\
\hline Uncoated samples & 1.05 & $2.6310^{-5}$ & 4.66 & 0.99 & $4.410^{-4}$ & 1110 & 0.62 & 0.28 \\
\hline Coated samples & 1.10 & $5.2810^{-4}$ & 25.99 & 0.90 & $1.0210^{-3}$ & 2590 & 0.65 & 1.72 \\
\hline
\end{tabular}

The coated API 5L X52 carbon steel sample showed higher resistances $\mathrm{R}_{f}$ and $\mathrm{R}_{c t}$ values (25.99 and $2590 \Omega \mathrm{cm}^{2}$ respectively) compared with those obtained for substrate without oxygen plasma treatment $\left(4.66\right.$ and $\left.1110 \Omega \mathrm{cm}^{2}\right)$. These indicated that oxide films became more protective (probably more thick and compact) with oxygen plasma treatment. Moreover, higher capacitance value was obtained for the coated sample $\left(1.72 \mathrm{mF} \mathrm{cm}^{-2}\right)$. Generally, oxide films with high thickness have capacitance with high magnitude [30].

The above results may indicate that the oxygen plasma treatment modifies the passive oxide film properties on API $5 \mathrm{~L} \mathrm{X52} \mathrm{carbon} \mathrm{steel.} \mathrm{This} \mathrm{latter} \mathrm{seems} \mathrm{to} \mathrm{have} \mathrm{quite} \mathrm{high}$ corrosion resistance and consequently, best corrosion protection comparing to the freely corroded substrate.

The whole electrochemical results showed a good improvement of API 5L X52 carbon steel after coating with oxygen plasma. A similar process of steel pieces treatment through argon or hydrogen plasma, tested in a $3.5 \% \mathrm{NaCl}$ solution, has given clear improvement against corrosion [21].

\section{Conclusions}

Oxygen plasma of API 5L X52 carbon steel has improved significantly its mechanical, microstructural and chemical properties. The glow electric discharge yielded black color of steel's surface. SEM observations on the formed deposit showed swellings aspect; their composition given by EDS reveals essentially iron and oxygen, it has been demonstrated that it is the hematite $\left(\mathrm{Fe}_{2} \mathrm{O}_{3}\right)$ [31] which was the result of combination of implanted oxygen with steel's iron atoms.

Oxygen plasma treatment improved superficial hardness of the studied steel, which proved by the significant increase of hardness after treatment.

The effect of the oxide film formed by oxygen plasma treatment on the corrosion API 5L X52 steel in NaCl 3\% were studied. Comparative studies were carried out on the coated and freely corroded samples. Immersion corrosion essays showed that coated steel presented weight losses and weak pitting percentages that recorded for uncoated steel. Potential corrosion showed cathodic behavior of the coated electrode. This latter presents a significant increase of linear polarization resistance. The electrochemical-impedance spectra were constituted of two overlapping capacitive loops. An equivalent circuit assumes that the passive film (oxide) recovering the metal in addition to charge transfer reaction, occurring on the interface carbon steel/solution, can be used to describe these diagrams. The higher values of the charge transfer resistance and film resistance were obtained after oxygen plasma treatment. Consequently, the hematite formed on API 5L X52 steel as result of oxygen plasma treatment improves considerably the hardness and the corrosion resistance of the studied steel.

\section{REFERENCES}

[1] G. Trabanelli, Corrosion 47 (1991) 410-419.

[2] M. Lagrenée, B. Mernari, M. Bouanis, M. Traisnel, F. Bentiss, Corr. Sci. 44 (2002) 573-588.

[3] M.A. Hegazy, H.M. Ahmed, A.S. El-Tabei; Corr. Science 53 (2011) 671-678

[4] M. Heydari, M. Javidi, Corr. Sci. 61 (2012) 148-155

[5] G.K. Wolf, Surf. Coat. Technol. 83 (1996) 1

[6] F. Noli, P. Missaelides, G. Giorginis, H. Baumann, A.Hatzidimitriou, Nucl. Instr. and Meth. B 95 (1995) 197.

[7] A.G. Duffy, L. Clapham, M.C. Ridgway, J.L. Whitton, Surface and Coating Tecshnology 83 (1996) 189

[8] S.K. Dhoke and A.S. Khana, Corr. Sci., 51(2009)6-20

[9] A.A. Akl, Applied surface Science, 221(2004)319

[10] E.L. Miller, D. Paluselli, B. Marsen and R.E. Rocheleau, Thin solid films, 466(2004)307

[11] H.R. Rezaie, R. Naghizadeh, N. Farrokhnia and M. Sobhani, Ceramics international, 35(2009)679-684

[12] F.J Pérez, L. Martinez, M.P. Hierro, C. Gomez, A.L. Portela, G.N. Pucci, D. Duday, J. Lecomte-Beckers and Y. Greday, Corr. Sci., 48(2006)472-480

[13] A. Alsaran, H. Altun, M. Karakan and A. Çelik, Surface and Coatings Technology 176(2004)344-348

[14] F.S. Shieu, M.J. Deng and S.H. Lin, Corrosion Science, 40(1998)1267-1279

[15] Kou Hyun Lee, Ki Suk Nam, Pyung Woo Shin, Deuk Yong Lee and o-Seung Song, Materials letters 57(2003)260-2065

[16] Y. Li, L. Wang, D. Zhang and L. Shen, Appl. Surf. Sci., 256(2010)4149-4152

[17] J. Nagahama and H. Yumoto, Surface and Coatings Technology, 169-170(2003)658-661

[18] Yong Jun Parka, K.M.A. Sobahana and Chang Kwon Hwangbo, Surface and Coatings Technology, 203(2009)2646-2650 
[19] M. Booth in Coatings and Surface treatment for Corrosion and Wear Resistance, K.N. Strafford, P.K. Datta and C.G. Googan ed., Ellis Horwood Ltd, Chichester, (1984)150-163

[20] L. Tan, R.A. Dodd, W.C. Crone, Biomaterials, 24(2003)3931-3939

[21] J.M. Williams, L. Riester, R. Pandey and A.W. Eberhardt, Surface and Coatings Technology, 88(1996)132-138

[22] Lei M.K., Zhu X.M. Surface and Coatings Technology, 193(2005)22-28.

[23] J. H Shina, D. S Lim and H.S Ahnb, Surface, 133-134(2000)103-410

[24] D. Landolt, in: Presses Polytechniques et Universitaires Romandes (Ed.), Corrosion et Chimie de Surfaces des Métaux, Trait_edes Matériaux, Vol. 12, 1993 (Chapter 5).
[25] M. Bojinov, G. Fabricius, T. Laitinen, T. Saario, Electrochim. Acta 44 (1999) 4331.

[26] K. Jüttner, W.L. Lorenz, W. Paatsch, Corros. Sci. 29 (1989) 279.

[27] J. Pan, C. Leygraf, R.F.A. Jargelius, J. Linden, Oxid. Met.50 (1998) 431.

[28] E.M.A. Martini, I.L. Muller, Corros. Sci. 42 (2000) 443.

[29] Bouckamp BA (1993) Users Man. Equivalent circuit ver. 4.51, Fac of chem. Tech., Univ of Twente, The Netherlands

[30] E. Sosa, V. Garcia-Arriaga, H. Castaneda, Electrochimica Acta 51 (2006) 1855-1863

[31] M.J Hernández Gayosso, G Zavala Olivares, N Ruiz Ordaz, C Juárez Ramirez, R. García Esquivel, A Padilla Viveros, Electrochimica Acta, 49 (2004) 4295-4301. 